\title{
The Comparison of Short-Term Therapeutic Effects of Acute Low-Tone Sensorineural Hearing Loss according to Steroid Capacity
}

\author{
Se A Lee ${ }^{1}$, Seung Jae Lee ${ }^{1}$, Do Young Jung ${ }^{2}$, Bo Gyung Kim ${ }^{1}$, Chi kyou Lee ${ }^{1}$, \\ Seong Jun Choi ${ }^{1}$, Byung Don Lee ${ }^{1}$, Kyurin Hwang ${ }^{1}$, and Jong Dae Lee ${ }^{1}$ \\ ${ }^{1}$ Department of Otolaryngology-Head and Neck Surgery, Soonchunhyang University College of Medicine, Bucheon; and ${ }^{2}$ Department of \\ Otorhinolaryngology-Head and Neck Surgery, Konyang University College of Medicine, Daejeon, Korea
}

\section{급성 저주파 감각신경성 난청에서 스테로이드 용량에 따른 단기적 치료 효과 비교 \\ 이세아 ${ }^{1} \cdot$ 이승재 $^{1} \cdot$ 정도영 $^{2} \cdot$ 김보경 $^{1} \cdot$ 이치규 $^{1} \cdot$ 최성준 $^{1} \cdot$ 이병돈 $^{1} \cdot$ 황규린 $^{1} \cdot$ 이종대 $^{1}$ \\ 순천향대학교 의과대학 이비인후과학교실, ${ }^{1}$ 건양대학교 의과대학 이비인후과학교실 ${ }^{2}$}

\author{
Received May 31, 2017 \\ Revised August 4, 2017 \\ Accepted August 23, 2017 \\ Address for correspondence \\ Jong Dae Lee, MD, PhD \\ Department of Otolaryngology- \\ Head and Neck Surgery, \\ Soonchunhyang University \\ College of Medicine, \\ Bucheon Hospital, 170 Jomaru-ro, \\ Bucheon 14584, Korea \\ Tel $+82-32-621-5054$ \\ Fax $+82-32-621-5018$ \\ E-mail ljdent@schmc.ac.kr
}

\begin{abstract}
Background and Objectives Acute low-tone sensorineural hearing loss refers to a condition wherein thresholds increase only at low frequencies in pure-tone audiometry. Systemic steroid treatment is commonly used for acute low-tone sensorineural hearing loss without vertigo, but there has been no established treatment in most clinical researches. The purpose of this study is to compare and analyze the short-term effects of high- and half-dose oral steroid therapy on patients suffering from acute low-tone sensorineural hearing loss without vertigo.

Subjects and Method Forty-six patients diagnosed with acute low-tone sensorineural hearing loss were divided into two groups and treated with high-dose (24 patients) and half-dose (22 patients) steroids, respectively. A retrospective analysis was conducted on their medical records. Results There were no significant differences between the two groups in any of the following: age, sex ratio, duration of symptoms before treatment, pure-tone hearing thresholds, low frequency hearing thresholds and speech intelligibility. However, both groups showed significant differences in hearing thresholds before and after treatment. In addition, no significant difference was noted in the recovery and recurrence rate between the two groups.

Conclusion According to the results of this study, there is no difference in treatment effect between the high- and half-dose groups. Therefore, half-dose steroids may be used as a treatment option for acute low tone sensorineural hearing loss.
\end{abstract}

Korean J Otorhinolaryngol-Head Neck Surg 2018;61(4):177-81

Key Words Low-tone $\cdot$ Sensorineural hearing loss $\cdot$ Steroid.

\section{서 론}

급성 저주파 감각신경성 난청(acute low-tone sensorineural hearing loss)은 순음 청력 검사상 저주파에 국한되어 역치가

This is an Open Access article distributed under the terms of the Creative Commons Attribution Non-Commercial License (http://creativecommons.org/licenses/by-nc/4.0) which permits unrestricted non-commercial use, distribution, and reproduction in any medium, provided the original work is properly cited.
증가하는 것을 말한다. 특발성 돌발성 난청(idiopathic sudden sensorineural hearing loss)의 한 종류로 분류하기도 하나, 어지럼증이 동반된 경우에는 메니에르병 진단에 따라 치료하 기도 한다. ${ }^{1,2)}$ 이러한 급성 저주파 감각신경성 난청 환자는 난 청보다 이충만감이나 이명 증상을 호소하는 경우가 더 많다. 전형적인 돌발성 난청보다 청력 회복에 대한 치료 결과는 더 좋지만, 재발이 더 흔하다는 점에서 차이를 보인다. ${ }^{1,3)}$ 
아직 급성 저주파 난청의 병태생리는 확실하게 밝혀지지 않 았다. 메니에르병의 초기 증상이거나, 내림프 수종(endolymphatic hydrops) 중에서 와우에만 수종이 발생한 경우(cochlear hydrops)일 수도 있으며 혹은 저주파를 담당하는 와우의 첨 부에만 병변이 생긴 돌발성 난청일 수도 있다.)

대부분의 임상 연구에서 어지럼이 없는 급성 저주파 난청 치료에 대해 경구 또는 고실 내 스테로이드 주입술을 주로 사 용하고 있고, ${ }^{1-8)}$ 일부에서 이뇨제를 단독으로 투여하거나 경 구 스테로이드와 함께 복용하도록 하고 있다. ${ }^{57,8)}$ 그러나 아직 치료가 확실히 정립되어 있지 않고, 주로 쓰는 스테로이드에 대하여서도 용량에 대해 정확한 진료지침이 확립되어 있지 는 않다. 고용량 스테로이드 투여는 청력 회복에 매우 효과적 이지만, 환자의 기존 질병을 악화시킬 수 있고, 그 외에도 몇 가지 위장 관계, 근골격계 등의 부작용을 일으킨다고 보고된 바 있다. ${ }^{9,10)}$ 외국의 몇몇 임상 연구에서 스테로이드 용량에 따른 치료에 대한 결과가 보고된 바 있으나, ${ }^{3,5)}$ 국내에서 용량 을 줄인 스테로이드 요법에 대한 보고는 없다. 이에 본 연구에 서는 어지럼증을 동반하지 않는 급성 저주파 감각신경성 난 청 환자들을 대상으로 하여, 고용량과 절반 용량의 스테로이 드 경구요법 치료의 단기 효과를 비교 분석하고자 하였다.

\section{대상 및 방법}

\section{대 상}

2010년 3월부터 2016년 12월까지 갑작스러운 이명, 이충만 감, 난청 등의 증상을 주소로 순천향대학교병원 이비인후과 에 내원한 환자 중, 어지럼이 동반되지 않고 고막 소견이 정상 이며, 청력 검사상 일측성 저주파 감각신경성 난청으로 진료 받은 18 세 이상 성인 환자들의 의무기록을 후향적으로 분석 하였다. 본 연구에서 급성 저주파 난청의 진단은 내원 1 주 이 내에 발생한 증상과 함께 순음 청력 검사상 $250,500 \mathrm{~Hz}$ 의 저주파 영역에서 합계 $50 \mathrm{~dB} \mathrm{HL}$ 이상 일측성 감각신경성 난 청을 보이며, $2,4,8 \mathrm{kHz}$ 의 청력 역치의 합이 $60 \mathrm{~dB} \mathrm{HL}$ 이하 의 정상 청력을 보이는 경우로 정의하였다. ${ }^{8,11}$

양측성이거나, 이전에 난청이나 어지럼증 병력이 있는 자, 기존 돌발성 난청의 기준에 부합하는 자, 메니에르병, 급성 또 는 만성 중이염, 당뇨, 스테로이드 치료 과거력 및 난청의 가족 력이 있는 자는 제외하였다.

\section{치료방법 및 평가}

총 46명의 환자 중 경구 고용량 스테로이드 제제로 치료한 군은 22 명, 절반 용량 스테로이드 제제로 치료한 군은 24 명이 었다. 스테로이드 용법은 methylprednisolone을 고용량 그룹
은 하루 $48 \mathrm{mg}$, 절반 용량 그룹은 $24 \mathrm{mg}$ 각각 5 일간 사용 후 감량하였다. 초기에 환자들에게 고용량 요법으로 사용하다가 나중에 저용량으로 써도 효과가 좋아서 자료를 모아 보니 비 슷한 결과를 보여 후향적으로 결과를 분석하였다. 환자들은 치료 후 7 14일 사이 외래 방문일에 문진, 진찰, 순음 청력 검 사, 어음 청력 검사를 시행하여 치료 효과를 확인하였다. 환 자의 연령 및 성비, 치료 전 증상의 지속 기간, 내원 당시 저주 파 난청의 정도, 치료 후 청력의 회복 정도를 비교하였고, 순 음 청력 검사는 $250,500,1 \mathrm{k}, 2 \mathrm{k}, 4 \mathrm{k}, 8 \mathrm{k} \mathrm{Hz}$ 의 주파수를 검사하였다. 재발은 환자가 완전 회복 후에 같은 증상으로 내 원하여 검사상 저음역 난청을 보이는 경우로 판단하였고 조 사 시점인 2017년 2월까지를 기준으로 하였다.

청각학적인 변화는 치료 전과 치료 후의 순음 청력 검사상 $250,500 \mathrm{~Hz}$ 의 저주파 역치를 비교하였다. 완전 회복(complete recovery)은 치료 후 $500 \mathrm{~Hz}$ 이하 모든 저주파에서 청 력 역치가 정상범위인 $20 \mathrm{~dB} \mathrm{HL}$ 이하로 회복된 경우로 정의하 였고, 부분 회복(partial recovery)은 치료 후 $500 \mathrm{~Hz}$ 이하 모 든 저주파의 청력 역치가 $20 \mathrm{~dB} \mathrm{HL}$ 이하로 회복된 것은 아니 지만, 치료 전과 비교하여 저주파의 청력 역치가 $10 \mathrm{~dB} \mathrm{HL}$ 이상 감소한 경우로 정의하였다. 그리고 모든 저주파에서 치 료 전후의 청력 역치 차이가 $10 \mathrm{~dB} \mathrm{HL}$ 미만으로 감소하거나 $10 \mathrm{~dB} \mathrm{HL}$ 이하로 증가한 경우를 불변(unchanged)으로 정의 하였다. 단기간 치료 후에 효과가 없는 환자들은 고실 내 스 테로이드 주입술을 시행하였다.

\section{통계분석}

두 군 간의 임상적 특성의 통계적 차이를 검정하기 위하여 Student's t-test 또는 Mann-Whitney U test 및 Fisher's exact test를 이용하였고, 군별 치료 전후 청력 역치 변화에 유의한 차 이가 있었는지 검정하기 위하여 Wilcoxon's signed-rank test 를 수행하였다.

모든 통계적인 검정은 양측 검정을 기반으로 유의수준 0.05 보다 작은 유의 확률을 보이는 경우를 유의한 것으로 간주하 였으며, 통계분석은 R(version 3.1.3; The R Foundation for Statistical Computing, Vienna, Austria)을 이용하였다.

\section{결 과}

경구 스테로이드 제제의 절반 용량으로 치료한 24명과 고용 량으로 치료한 22 명 간에 연령, 성비, 치료 전 증상의 지속 기 간, 순음 청력 역치, 저주파 청력 역치, 어음 명료도는 유의한 차이를 보이지 않았다(Table 1). 절반 용량 치료군에서 1명이 고혈압이 있었고, 고용량 치료군에서는 1 명이 신장암으로 진 
단받고 수술받은 과거력이 있었다.

절반 용량 치료군에서 $250,500 \mathrm{~Hz}$ 청력 역치의 합계는 치 료 전 $68.3 \pm 13.6 \mathrm{~dB} \mathrm{HL}$, 치료 후 $48.5 \pm 25.3 \mathrm{~dB}$ HL로 치료 전후 유의한 차이를 보였고 $(p<0.001)$, 고용량 치료군에서도

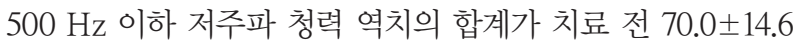
$\mathrm{dB} \mathrm{HL}$, 치료 후 $46.4 \pm 27.4 \mathrm{~dB}$ HL로 치료 전후 유의한 차이 를 보였다 $(p<0.001)$. 각각 $250,500 \mathrm{~Hz}$ 및 저주파 청력 역치 합에서 치료 전후 평균 역치 차이는 두 군 간 유의한 차이가 없었다(Table 2).

절반 용량 치료군에서 완전히 회복된 경우는 21 명, 변화 없 는 경우가 3 명이었고, 고용량 치료군에서 완전히 회복된 경우 는 19명, 변화 없는 경우가 3명이었다. 두 군 모두에서 부분 회복된 경우는 없었다. 절반 용량 치료군에서의 회복률은 $87.5 \%$, 고용량 치료군에서의 회복률은 $86.4 \%$ 로 두 군 간의 회
복률에 유의한 차이는 없었다 $(p=1)$ (Fig. 1).

전체 환자 중, 3 명의 환자에서 재발의 소견을 보였다. 절반 용량 치료군에서 1 명(4.2\%), 고용량 치료군에서 2 명(9.1\%)의 환자가 재발 소견을 보였다. 재발률에 대해 두 군 간의 유의 한 차이는 없었다 $(p=0.6)$ (Table 3$)$.

\section{고 찰}

돌발성 감각신경성 난청(sudden sensorineural hearing loss)은 이비인후과에서 비교적 흔히 볼 수 있는 질환으로 연 간 10 만 명당 5 20명 정도의 발병률을 보인다. ${ }^{12)}$ 이 중에서도 저주파 영역에만 국한되어 청력감소를 보이는 경우도 종종 볼 수 있으며, 문헌에 따라 급성 저음역(acute low tone) 감각 신경성 난청, ${ }^{1-3,8)}$ 돌발성 저음역(sudden low tone) 감각신경성

Table 1. Baseline characteristics

\begin{tabular}{|c|c|c|c|c|}
\hline Variable & Total $(n=46)$ & Half dose $(n=24)$ & High dose $(n=22)$ & $p$-value \\
\hline Age (year) & $36.8 \pm 11.3$ & $38.5 \pm 9.7$ & $35.0 \pm 12.8$ & $0.295^{*}$ \\
\hline $\operatorname{Sex}(\%)$ & & & & $>0.999$ \\
\hline Male & $11(23.9)$ & $6(25.0)$ & $5(22.7)$ & \\
\hline Female & $35(76.1)$ & $18(75.0)$ & $17(77.3)$ & \\
\hline Duration from onset to initial visit (day) & $4.1 \pm 2.2$ & $3.7 \pm 2.3$ & $4.5 \pm 2.1$ & $0.330^{+}$ \\
\hline Pure tone averages ( $\mathrm{dB} \mathrm{HL})$ & $18.0 \pm 6.5$ & $17.8 \pm 6.5$ & $18.4 \pm 6.6$ & $0.762^{*}$ \\
\hline Sum of low frequencies $\leq 500 \mathrm{~Hz}(\mathrm{~dB} \mathrm{HL})$ & $69.1 \pm 14.0$ & $68.3 \pm 13.6$ & $70.0 \pm 14.6$ & $0.691^{*}$ \\
\hline Speech discrimination score (\%) & $95.4 \pm 5.1$ & $95.0 \pm 5.7$ & $95.8 \pm 4.5$ & $0.736^{\dagger}$ \\
\hline
\end{tabular}

Data were reported as mean \pm standard deviation for continuous variables and frequency (percentage) for categorical variable. The pure tone averages are calculated as one-fourth the sum of hearing at $500 \mathrm{~Hz}, 1 \mathrm{kHz} \times 2$, and $2 \mathrm{kHz}$. *p-values were calculated by Student's t-test, ${ }^{\dagger} p$-values were calculated by Mann-Whitney U test. $p$-value for sex was calculated by chi-square test

Table 2. Comparision of pure tone thresholds after the treatment according to treatment group

\begin{tabular}{llcr}
\hline \multirow{2}{*}{ Frequency $(\mathrm{Hz})$} & Treatment & $\begin{array}{c}\text { Average improvement in hearing } \\
\text { thresholds after treatment }(\mathrm{dB} \mathrm{HL})\end{array}$ & $\mathrm{p}$-value \\
\hline 250 & Half dose $(\mathrm{n}=24)$ & $27.3 \pm 13.3$ & $0.747^{\dagger}$ \\
& High dose $(\mathrm{n}=22)$ & $26.1 \pm 13.7$ & $0.811^{*}$ \\
500 & Half dose $(\mathrm{n}=24)$ & $21.2 \pm 13.9$ & $20.2 \pm 14.9$ \\
& High dose $(\mathrm{n}=22)$ & $8.5 \pm 25.3$ & $0.825^{\dagger}$ \\
& Half dose $(\mathrm{n}=24)$ & $46.4 \pm 27.4$ & \\
& High dose $(\mathrm{n}=22)$ & & \\
\end{tabular}

Data were reported as mean \pm standard deviation. $* p$-values were calculated by Student's $t$-test, ${ }^{\dagger} p$-values were calculated by Mann-Whitney U test

Table 3. Treatment results and recurrence rate according to treatment group

\begin{tabular}{|c|c|c|c|c|}
\hline Variable & Total $(n=46)$ & Half dose $(n=24)$ & High dose $(n=22)$ & $p$-value \\
\hline Results (\%) & & & & $>0.999$ \\
\hline Unchanged & $6(13.0)$ & $3(12.5)$ & $3(13.6)$ & \\
\hline Complete recovery & $40(87.0)$ & $21(87.5)$ & $19(86.4)$ & \\
\hline Recurrence (\%) & & & & 0.6 \\
\hline Absence & $43(93.5)$ & $23(95.8)$ & $20(90.9)$ & \\
\hline Presence & $3(6.5)$ & $1(4.2)$ & $2(9.1)$ & \\
\hline
\end{tabular}

Data were reported as frequency (percentage). p-values were calculated by Fisher's exact test 

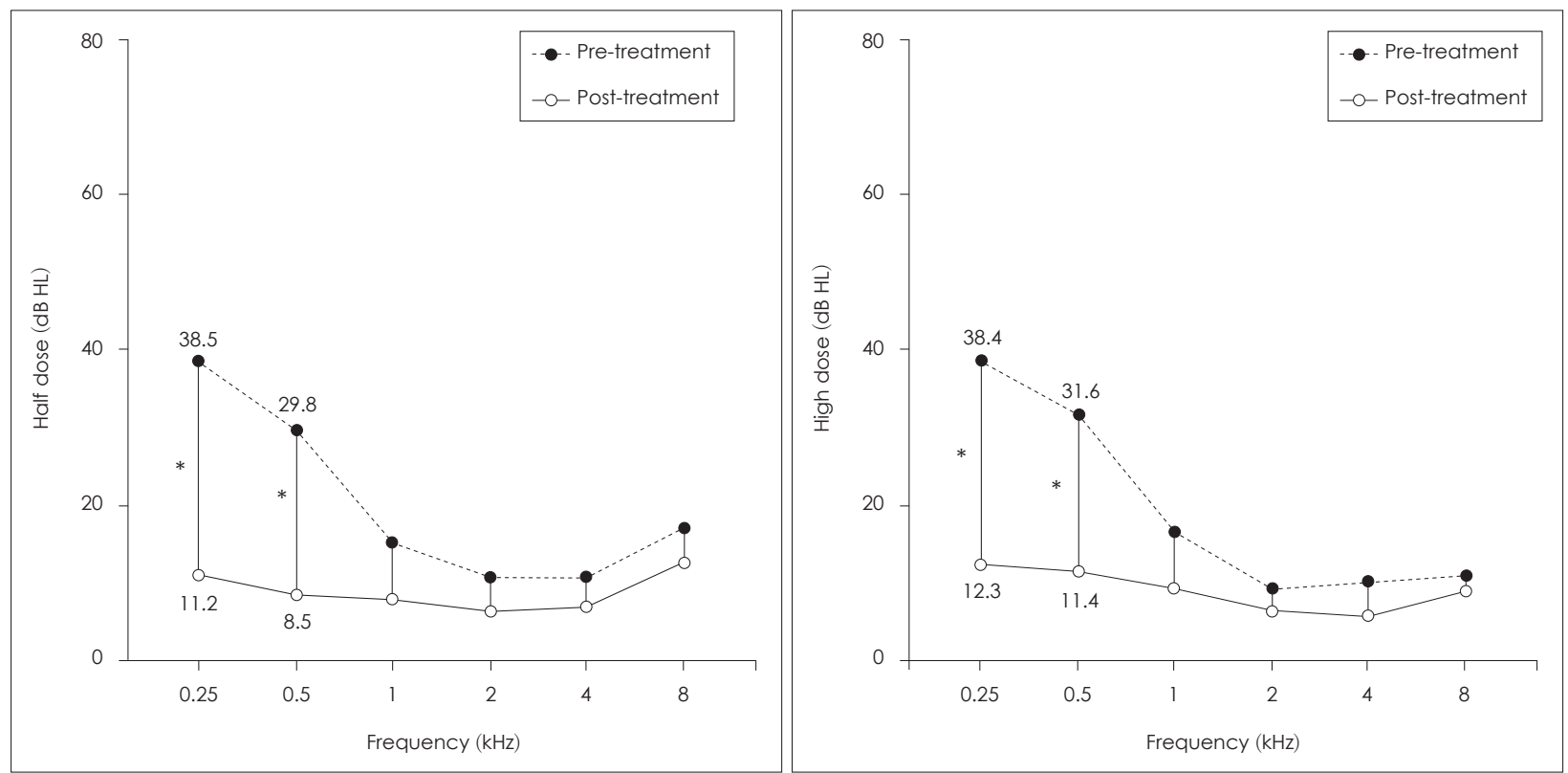

Fig. 1. Comparison of pure tone thresholds between pre and post treatment according to treatment group ( $p$-values were calculated by Wilcoxon's signed rank test. $\left.{ }^{*} p<0.05\right)$.

난청, ${ }^{13)}$ 와우형 수종(cochlear hydrops), ${ }^{14)}$ 와우형 메니에르 병ㄷ) 등 다양하게 보고되고 있다. 일반적으로 어지럼증을 동 반하지 않는 급성 저주파 감각신경성 난청은 난청, 이명, 이충 만감, 자가강청 등을 주 증상으로 내원하여 정상 고막 소견 을 보이면서 순음 청력 검사상 저주파에 국한된 청력감소를 나타낸다. 돌발성 난청보다 예후가 좋으나 9 47\%에서 재발 하고 $10 \%$ 내외에서 메니에르병으로 진행되는 것으로 알려져 있다. ${ }^{1,16,17)}$

급성 저주파 난청의 진단기준이 아직 확실히 정립되지는 않 았으나, 대부분의 임상 연구에서 순음 청력 검사상, $125 \mathrm{~Hz}$ 를 포함한 $250,500 \mathrm{~Hz}$ 의 역치 증가를 포함하고 있다. ${ }^{1-8)} \mathrm{Amer}-$ ican Speech-Language-Hearing Association에서 제안한 청 력 검사 지침서에서 저주파 난청이 있을 때 반드시 $125 \mathrm{~Hz}$ 에 서의 청력 역치를 확인하도록 권장했지만, American National Standards Institute에서 발표한 청력 검사 표준안에서는 125 $\mathrm{Hz}$ 역치 측정에 대해 강제성이 없고 특수한 상황에서 검사해 볼 수도 있다고 기술되어 있다. ${ }^{18)}$ 또한 국내 연구들에서도 일 반적인 외래 환자를 대상으로 순음 청력 검사를 시행할 때 $125 \mathrm{~Hz}$ 의 역치는 측정하지 않고 발표되었다. ${ }^{11,16,19)}$ 본 연구에 서도 저주파 감각신경성 난청의 기준으로 순음 청력 검사상 $250,500 \mathrm{~Hz}$ 의 저주파 영역 청력 역치의 합계 $50 \mathrm{~dB} \mathrm{HL}$ 이상 의 일측성 저주파 감각신경성 난청을 보이면서, $2,4,8 \mathrm{kHz}$ 의 청력 역치의 합이 $60 \mathrm{~dB} \mathrm{HL}$ 이하의 정상 청력을 보이는 경 우로 정의하였다.

어지럼증이 동반되지 않는 급성 저주파 감각신경성 난청에
서 주로 사용되는 약물은 스테로이드 제제이다. Fuse 등흐는 급성 저주파 난청의 치료에 고용량 스테로이드를 사용하였고, Alatas $^{6}$ 는 고실 내 주사가 급성 저주파 난청에 효과적이라고 보고하였다. 스테로이드의 항염증 효과 및 면역억제 효과가 청력 회복에 큰 역할을 하는 것으로 생각된다. ${ }^{20)}$ 하지만, 스 테로이드 전신 투여는 환자의 기존 질병을 악화시킬 수 있으 며 와우 영역에 국소적으로 작용하지 못한다는 단점이 있 다. ${ }^{10)} \mathrm{Min}$ 등 ${ }^{9}$ 은 경구 투여의 합병증으로 비출혈, 약물 유발 성 간 기능장애, 여드름, 위장관염, 둔부 농양 형성 등을 보고 하였으며, 스테로이드의 전신 투여로 인한 무혈성 괴사를 보 고한 바 있다. ${ }^{10)}$ 이러한 부작용은 흔하지는 않지만 흔히 사용 하는 용량인 40 60 mg의 prednisone 용량으로도 발생할 수 있으므로 치료 전 환자에게 부작용을 설명하고 가급적이면 저 용량 사용을 권하였다. ${ }^{21)}$ 스테로이드 전신 부작용을 고려하여 저음역 감각신경성 난청에서 고용량 스테로이드 치료가 prednisone $30 \mathrm{mg}$ 이하의 저용량 스테로이드 치료보다 좀 더 효 과적이나 통계적으로 유의한 차이는 보이지 않는다는 연구 결과를 바탕으로 저용량 스테로이드 치료 시작 후 실패 시 고용량 스테로이드를 투여하자고 제안한 보고도 있다. ${ }^{5)}$

Morita 등 ${ }^{8}$ 은 급성 저주파 감각신경성 난청 치료에서 스테 로이드-이뇨제 복합요법이 스테로이드 또는 이뇨제 단독요법 보다 치료 효과가 좋았다고 보고하였으나, Chang 등 22)은 스 테로이드-이뇨제 복합요법과 스테로이드 단독요법과 차이가 없다고 보고하였다. 또한 Suzuki 등ํㅡㄴ 급성 저주파 감각신 경성 난청 환자의 다변량 분석을 통한 예후 분석에서 이뇨제 
는 스테로이드보다 예후에 영향을 미치지 않지만, 스테로이 드는 용량에 상관없이 치료 효과가 있다고 보고하였다. 본 연 구에서 환자들에게 이뇨제는 사용하지 않았으며 경구 스테로 이드의 용량에 따른 치료 효과의 차이가 있는지 확인하기 위 해 결과를 분석하였다. 절반 용량 치료군에서의 회복률은 $87.5 \%$, 고용량 치료군에서의 회복률은 $86.4 \%$ 로 두 군 간의 회복률에서 유의한 차이를 보이지 않았다. 이는 급성 저주파 감각신경성 난청의 다른 연구들에서 발표한 회복률인 63.3 79.0\%보다 높게 나왔는 데, ${ }^{3,8,11,16)}$ 이는 본 연구의 표본 수가 많지 않은 것과 진단기준이 타 연구들에 비해 난청의 정도가 심하지 않기 때문으로 생각된다. 또한 급성 저주파 감각신경성 난청에서 부분 회복은 돌발성 난청에 비해 매우 낮은 편으로 보고되나, ${ }^{3,8,11,16)}$ 본 연구에서 회복된 환자들이 모두 완전 회복을 보이는 것도 같은 이유로 설명된다.

본 연구에서 절반 용량 치료군에서 1명(4.2\%), 고용량 치료 군에서 2 명 $(9.1 \%)$ 의 환자가 재발 소견을 보였다. 이는 기존의 연구를 통해 흔히 알려진 재발률 9 47\%보다 낮은 수치이 다. ${ }^{1,16,17)}$ 이는 본 연구가 후향적 연구로 추적관찰이 짧고 재발 된 환자가 본원에 내원하지 않은 이유도 있을 것으로 생각된다.

본 연구는 몇 가지 제한점을 가지고 있다. 앞서 말한 바와 같이, 기존 연구보다 본 연구의 완전 회복률이 높고 재발률은 낮은 편으로, 환자에 대한 선택 편향이 우려되나, 후향적 차트 리뷰이고 표본 수가 적기 때문에 향후 전향적인 이중 맹검 연 구를 통하여 추가 검증이 필요하다. 또한 $125 \mathrm{~Hz}$ 를 진단기준 에 포함시키지 않은 점도 제한점에 해당된다.

\section{REFERENCES}

1) Yamasoba T, Kikuchi S, Sugasawa M, Yagi M, Harada T. Acute lowtone sensorineural hearing loss without vertigo. Arch Otolaryngol Head Neck Surg 1994;120(5):532-5.

2) Imamura S, Nozawa I, Imamura M, Murakami Y. Clinical observations on acute low-tone sensorineural hearing loss. Survey and analysis of 137 patients. Ann Otol Rhinol Laryngol 1997;106(9):746-50.

3) Fuse T, Aoyagi M, Funakubo T, Sakakibara A, Yoshida S. Short-term outcome and prognosis of acute low-tone sensorineural hearing loss by administration of steroid. ORL J Otorhinolaryngol Relat Spec 2002;64(1):6-10.

4) An YH, Lee ES, Kim HJ, Kang YK, Oh HS, Shim HJ. Significance of $125 \mathrm{~Hz}$ pure-tone thresholds for acute low frequency sensorineural hearing loss. Korean J Otorhinolaryngol-Head Neck Surg 2016; 59(8):583-7.

5) Suzuki M, Otake R, Kashio A. Effect of corticosteroids or diuretics in low-tone sensorineural hearing loss. ORL J Otorhinolaryngol Relat Spec 2006;68(3):170-6.

6) Alatas N. Use of intratympanic dexamethasone for the therapy of low frequency hearing loss. Eur Arch Otorhinolaryngol 2009;266 (8):1205-12.

7) Selivanova OA, Gouveris H, Victor A, Amedee RG, Mann W. Intratympanic dexamethasone and hyaluronic acid in patients with low-frequency and Ménière's-associated sudden sensorineural hearing loss. Otol Neurotol 2005;26(5):890-5.

8) Morita S, Suzuki M, Iizuka K. A comparison of the short-term outcome in patients with acute low-tone sensorineural hearing loss. ORL J Otorhinolaryngol Relat Spec 2010;72(6):295-9.

9) Min KH, Rhee CK, Jung JY, Suh MW. Characteristics of adverse effects when using high dose short term steroid regimen. Korean J Audiol 2012;16(2):65-70.

10) Park YS, Jeon EJ, Yeo SW, Park SN, Park JW, Kim KB. The effect of intratympanic steroid injection for sudden sensorineural hearing loss. Korea J Otolaryngol 2002;45(12):1136-40.

11) Roh KJ, Lee EJ, Park AY, Choi BI, Son EJ. Long-term outcomes of acute low-tone hearing loss. J Audiol Otol 2015;19(2):74-8.

12) Stachler RJ, Chandrasekhar SS, Archer SM, Rosenfeld RM, Schwartz SR, Barrs DM, et al. Clinical practice guideline: sudden hearing loss. Otolaryngol Head Neck Surg 2012;146(3 Suppl):S1-35.

13) Fushiki H, Junicho M, Aso $S$, Watanabe Y. Recurrence rate of idiopathic sudden low-tone sensorineural hearing loss without vertigo: a longterm follow-up study. Otol Neurotol 2009;30(3):295-8.

14) Hillman TM, Arriaga MA, Chen DA. Intratympanic steroids: do they acutely improve hearing in cases of cochlear hydrops? Laryngoscope 2003;113(11):1903-7.

15) Claes GM, De Valck CF, Van de Heyning P, Wuyts FL. Does 'cochlear Ménière's disease' exist? An electrocochleographic and audiometric study. Audiol Neurootol 2013;18(1):63-70.

16) Jung AR, Kim MG, Kim SS, Kim SH, Yeo SG. Clinical characteristics and prognosis of low frequency sensorineural hearing loss without vertigo. Acta Otolaryngol 2016;136(2):159-63.

17) Junicho M, Aso S, Fujisaka M, Watanabe Y. Prognosis of low-tone sudden deafness-does it inevitably progress to Meniere's disease? Acta Otolaryngol 2008;128(3):304-8

18) Working Group on Manual Pure-Tone Threshold Audiometry. Guidelines for manual pure-tone threshold audiometry. ASHA 1978; 20(4):297-301.

19) Kwak MY, Yu KK, Kang YK, Yoon SW, Shim HJ, An YH. Intratympanic steroid and oral diuretics combination therapy for acute low frequency sensorineural hearing loss without vertigo. Korean J Otorhinolaryngol-Heand Neck Surg 2015;58(1):19-24.

20) Park HH, Choi JH, Huh EJ, Lee TH, Nam JK, Kwon JK. Comparison of the effect of high-dose steroid with that of super-high-dose steroid therapy in sudden sensorineural hearing loss. Korean J Otolaryngol 2009;52(7):566-71.

21) Richards RN. Side effects of short-term oral corticosteroids. J Cutan Med Surg 2008;12(2):77-81.

22) Chang J, Yum G, Im HY, Jung JY, Rah YC, Choi J. Short-term outcomes of acute low-tone sensorineural hearing loss according to treatment modality. J Audiol Otol 2016;20(1):47-52. 